\title{
An Antegrade Perfusion Method for Cardiomyocyte Isolation from Mice
}

\author{
Mariko Omatsu-Kanbe ${ }^{1}$, Ryo Fukunaga ${ }^{1}$, Xinya $\mathbf{M i}^{1}$, Hiroshi Matsuura ${ }^{1}$ \\ ${ }^{1}$ Department of Physiology, Shiga University of Medical Science
}

\section{Corresponding Author}

Mariko Omatsu-Kanbe

m_omatsu@belle.shiga-med.ac.jp

\section{Citation}

Omatsu-Kanbe, M., Fukunaga, R., Mi, X., Matsuura, H. An Antegrade Perfusion Method for Cardiomyocyte Isolation from Mice. J. Vis. Exp. (171), e61866, doi:10.3791/61866 (2021).

\section{Date Published}

May 19, 2021

\section{DOI}

$10.3791 / 61866$

URL

jove.com/video/61866

\section{Abstract}

In basic research using mouse heart, isolating viable individual cardiomyocytes is a crucial technical step to overcome. Traditionally, isolating cardiomyocytes from rabbits, guinea pigs or rats has been performed via retrograde perfusion of the heart with enzymes using a Langendorff apparatus. However, a high degree of skill is required when this method is used with a small mouse heart. An antegrade perfusion method that does not use a Langendorff apparatus was recently reported for the isolation of mouse cardiomyocytes. We herein report a complete protocol for the improved antegrade perfusion of the excised heart to isolate individual heart cells from adult mice ( 8 - 108 weeks old). Antegrade perfusion is performed by injecting perfusate near the apex of the left ventricle of the excised heart, the aorta of which was clamped, using an infusion pump. All procedures are carried out on a pre-warmed heater mat under a microscope, which allows for the injection and perfusion processes to be monitored. The results suggest that ventricular and atrial myocytes, and fibroblasts can be well isolated from a single adult mouse simultaneously.

\section{Introduction}

Generally, the first step of the single cell isolation of dissected tissue involves mincing the tissue into small pieces, followed by the digestion of the connective tissue and extracellular matrix with enzymes. However, cardiomyocytes cannot be isolated with such a chopping method, as enrichment with extracellular matrix components, including collagen and elastin fibers, makes the myocardium too tough to mince, and the cardiomyocytes are highly sensitive to hypoxia and other changes in the microenvironment. Thus, using the Langendorff-based retrograde perfusion system ${ }^{1}$, a method of digesting the extracellular matrix with enzymes has been developed to isolate individual cardiomyocytes from the heart $^{2,3,4}$

In mouse models, Langendorff-based retrograde perfusion of the heart with enzymes is also used for the isolation of individual cardiomyocytes ${ }^{5,6,7,8}$. However, the cannulation of the small and thin mouse aorta and its mounting on the Langendorff apparatus to perform retrograde perfusion requires a high degree of skill, since the diameter of the aorta in the adult heart is approximately $1.2 \mathrm{~mm}$. Furthermore, it 
takes time to perform multiple experiments as the Langendorff apparatus should be cleaned before perfusing the next heart.

As an alternative to retrograde perfusion, a novel method for isolating cardiomyocytes from an adult mouse heart without a Langendorff apparatus was developed. This epochmaking method was based on the antegrade perfusion of the coronary arteries ${ }^{9}$. We recently improved each step of this antegrade protocol, such as the clamping of the aorta, needle insertion, and temperature control, and monitored all perfusion procedures with a microscope ${ }^{10}$. We herein report in detail the refinement of this antegrade perfusion method to shorten the time for isolation and provide a supplemental video. In this method, the perfusion of the heart takes approximately $7 \mathrm{~min}$ with $10 \mathrm{~mL}$ of the enzymes, and this short digestion period increases the viability of the cells. This is a simple method for isolating single heart cells at a high quality without requiring the addition of chemicals, such as 2,3-butanedione monoxime $(\mathrm{BDM})^{6,11}$ or taurine ${ }^{5,8}$. We believe that this method will lower the skill threshold of the technique and enhance the utility of mouse cardiomyocytes in basic research.

\section{Protocol}

All animal experiments conformed to the Guide for the Care and Use of Laboratory Animals published by the US National Institutes of Health (NIH Publication No. 85-23, revised 1996) and were approved by the institutional Review Board of the Shiga University of Medical Science Animal Care and Use Committee (approved No. 2019-3-7). The methods were carried out in accordance with approved guidelines.

\section{Instruments and solution}

NOTE: An outline of the experimental procedure is illustrated in a flow diagram (Supplementary Figure 1). An infusion pump (or syringe pump) should be used for the antegrade perfusion of the heart with a one-way flow. A peristaltic pump that creates a pulsating flow is not recommended.

\section{Before the experimental}

1. Mark the injection needle at a site approximately 3 $\mathrm{mm}$ from the tip with nail polish. After allowing it the air dry, keep it in the container at room temperature. A red or bright color is desirable to confirm the depth of insertion into the myocardium during perfusion.

2. Make the heart stand by cutting the lids off of 1.5-, 0.5- and 0.2-mL sample tubes and attaching the lids to the bottom of a $60-\mathrm{mm}$ culture dish with doublesided tape or adhesive. Fixation of three differentsized lids in one dish makes it possible to choose the appropriate one according to the size of the mouse heart. This heart stand can be reused after washing.

3. Make stock solution as shown in Table 1. Store the stock solutions at $4{ }^{\circ} \mathrm{C}$.

2. On the experiment day

NOTE: Cell isolation buffer (CIB) contains (in mM) 130 $\mathrm{NaCl}, 5.4 \mathrm{KCl}, 0.5 \mathrm{MgCl}_{2}, 0.33 \mathrm{NaH}_{2} \mathrm{PO}_{4}, 22$ glucose, 40 units/mL insulin and 25 HEPES ( $\mathrm{pH}$ adjusted to 7.4 with $\mathrm{NaOH}$ ); and Tyrode solution contains (in mM) 140 $\mathrm{NaCl}, 5.4 \mathrm{KCl}, 1.8 \mathrm{CaCl}_{2}, 0.5 \mathrm{MgCl}_{2}, 0.33 \mathrm{NaH}_{2} \mathrm{PO}_{4}, 5.5$ glucose and 5.0 HEPES (pH adjusted to 7.4 with $\mathrm{NaOH}$ ).

1. Prepare the CIB. Warm $160 \mathrm{~mL}$ of distilled water (DW) using a microwave to around $32{ }^{\circ} \mathrm{C}$ and then add $20 \mathrm{~mL}$ of $10 X$ CIB. After the addition of $0.79 \mathrm{~g}$ glucose and $10 \mu \mathrm{L}$ of insulin solution, adjust the $\mathrm{pH}$ using $1 \mathrm{M} \mathrm{NaOH}$ and bring to $200 \mathrm{~mL}$ with DW.

2. Prepare the enzyme mix solution (enzyme mix). Add $30 \mathrm{mg}$ of collagenase, $1.8 \mathrm{mg}$ of trypsin, $1.8 \mathrm{mg}$ of 
protease and $90 \mu \mathrm{L}$ of $100 \mathrm{mM} \mathrm{CaCl}_{2}$ stock solution to $30 \mathrm{~mL}$ of $\mathrm{CIB}$ (final $\mathrm{Ca}^{2+}$ concentration is $0.3 \mathrm{mM}$ ), mix, and keep it on ice. In mice $<4$ weeks old, reduce trypsin and protease to $0.9 \mathrm{mg}^{10}$. Warm at $37^{\circ} \mathrm{C}$ in a water bath before use.

3. Prepare the CIB-Ca ${ }^{2+}-\mathrm{BSA}$ solution. Add $30 \mathrm{mg}$ BSA and $90 \mu \mathrm{L}$ of $100 \mathrm{mM} \mathrm{CaCl} 2$ stock solution to $15 \mathrm{~mL}$ of CIB (final $\mathrm{Ca}^{2+}$ concentration is $1.2 \mathrm{mM}$ ), mix, filter through a $20-\mu \mathrm{m}$ filter, and keep it on ice.

4. Prepare the CIB-EGTA solution. After making the solutions described in steps 1.2.2 and 1.2.3, add 400 mM EGTA stock solution to the remaining CIB at a 1:1000 dilution (final EGTA concentration is 0.4 $\mathrm{mM}$ ), and mix. Fill the 35-mm culture dish and heart stand dish with CIB-EGTA and keep them on ice.

1. Pour approximately $20 \mathrm{~mL}$ of CIB-EGTA into a 30-mL glass beaker and stand a plastic transfer pipette in the beaker, keeping it on ice.

5. Prepare Tyrode solution. Add $100 \mathrm{~mL}$ of $10 \mathrm{X}$ Tyrode to $800 \mathrm{~mL}$ of DW and warm it using a microwave to around $32{ }^{\circ} \mathrm{C}$. After adding $0.99 \mathrm{~g}$ of glucose and 1.8 $\mathrm{mL}$ of $1 \mathrm{M} \mathrm{CaCl}_{2}$, adjust the $\mathrm{pH}$ using $1 \mathrm{M} \mathrm{NaOH}$ and bring to $1000 \mathrm{~mL}$ with $\mathrm{DW}$.

6. Prepare the cell resuspension solution. Add $30 \mathrm{mg}$ of BSA and $300 \mu \mathrm{L}$ of $50 \mathrm{X}$ antibiotics to $15 \mathrm{~mL}$ of Tyrode solution.

7. Prepare syringes. Fill the $20-\mathrm{mL}$ syringe connected with the flexible extension tube and the marked injection needle with CIB-EGTA. Fill the $30-\mathrm{mL}$ syringe with the warmed enzyme mix. Hold them both at $37^{\circ} \mathrm{C}$ until just before use.
8. Prepare the perfusion plate. Prewarm the heater mat under a stereoscopic microscope. Place the perfusion plate (lid of a multi-well culture plate) on the prewarmed heater mat. Prewarm the vascular clamp by placing it in the perfusion plate until use. Place the $60-\mathrm{mm}$ culture dish for pipetting and the cell strainer on the prewarmed heater mat as well.

\section{Antegrade perfusion of the mouse heart}

NOTE: The plastic transfer pipette used for sucking the heart should be soft and not be sharply tapered towards the tip. Choose a small vascular clamp with serration. The recommended instruments are listed in the Table of Materials.

1. Excision of the mouse heart and clamping the aorta NOTE: The adult mice (>8 weeks old) should be euthanized by an overdose of sodium pentobarbital (>300 mg/kg, intraperitoneal [i.p.] injection) with heparin (8000 unit/kg).

1. Excise the mouse heart quickly by sucking.

1. Open the thoracic cavity quickly to expose the heart. Cut the plastic transfer pipette, the tip of which is approximately the same size as, or slightly smaller than, the exposed heart (usually at a site approximately $1 \mathrm{~cm}$ from the $0.5-\mathrm{mL}$ mark towards the tip, but it depends on the heart size).

2. Suck the heart into the pipette, raise the pipette to create enough space to insert scissors, and excise the heart with curved scissors from the dorsal side, avoiding damaging the atria.

3. Immediately transfer the excised heart to the 30-mL glass beaker containing ice-chilled CIB- 
EGTA to stop the contraction. This procedure usually takes $<1 \mathrm{~min}$.

2. Cleaning around the aorta

1. Transfer the heart to a $35-\mathrm{mm}$ culture dish filled with ice-chilled CIB-EGTA and remove the lung and other visible tissues, and then transfer the roughly cleaned heart to the heart stand filled with chilled CIB-EGTA and place it with the apex down.

2. Under the stereoscopic microscope, remove the fat and connective tissues to clean around the aorta. If the length of the cut aorta is too long including the brachiocephalic artery, the left common carotid artery or the left subclavian artery, cut off the aorta just under the brachiocephalic artery to shorten it in order to proceed to the next step. This procedure usually takes approximately $4 \mathrm{~min}$.

3. Clamping the aorta and placing the clamped heart on the perfusion plate

1. Under the microscope, place the heart in the heart stand. The operator should face the anterior surface of the heart, pick up the end of the aorta with tweezers, and clamp the aorta near the atria with a small vascular clamp while gently pushing down on the aorta a bit.

2. Place the clamped heart on the perfusion plate with the anterior side up, and then cover it with a few drops of CIB-EGTA to keep it from drying out. This procedure usually takes $<20 \mathrm{~s}$.

2. Antegrade perfusion of the heart

NOTE: First, perfuse the heart with CIB-EGTA to discharge blood and prevent clotting.
1. Insert the injection needle and start perfusion to discharge blood

1. Set the 20-mL syringe filled with prewarmed CIB-EGTA connected to the flexible extension tube and a marked injection needle on the infusion pump. Start the pump at a slow rate of $0.5 \mathrm{~mL} / \mathrm{min}$ to carefully fill the needle and tube with CIB-EGTA and be sure to prevent any air from entering the tube.

2. Place the injection needle on the perfusion plate with the shorter side of the diagonal shape in front. Slide the needle towards the apex of the heart until it is touching it, and then carefully insert the needle near the apex of the left ventricle into the ventricular chamber without twisting. Do not detach the needle from the plate while performing insertion.

3. Watch the red mark to estimate the depth of the needle insertion. When the needle insertion is completed, blood flowing from the coronary artery should start to be discharged.

4. Fix the injection needle on the plate with tape, and increase the pump speed to $1 \mathrm{~mL} / \mathrm{min}$. This procedure usually takes approximately $30 \mathrm{~s}$. If the heart is perfused successfully, the flow of the CIB-EGTA in the capillary just under the epicardium can be seen under the microscope.

2. Perfusion the heart with enzyme mix

NOTE: During enzymatic perfusion, the depth of the inserted needle can be monitored by checking the red mark on the needle.

1. After perfusing 2-3 $\mathrm{mL}$ of CIB-EGTA to completely discharge blood from the coronary 
artery, change the perfusate to enzyme mix. Avoid allowing air bubbles to enter the tube. Check the flow of the enzyme mix, and ensure that the injection needle has not come out by checking the position of the red mark.

2. After 1-2 $\mathrm{mL}$ has been perfused, increase the pump speed to $1.5 \mathrm{~mL} / \mathrm{min}$. Remove the accumulated perfusate containing blood that has flowed out of the heart with a pipette from time to time.

NOTE: Over time, the myocardial wall will become translucent in some places and appear mottled, which is a sign of digestion of the extracellular matrix following successful perfusion. Another sign is the restarting of atrial beating caused by the presence of $\mathrm{Ca}^{2+}$ in the enzyme mix.

3. Stop perfusion when the total volume of the enzyme mix perfused is $10 \mathrm{~mL}$.

\section{Isolation of individual heart cells}

\section{Dissociating heart cells}

1. After perfusion with the enzyme mix, transfer $10 \mathrm{~mL}$ of the enzyme mix remaining in the syringe to a 60 $\mathrm{mm}$ culture dish placed on the heater mat and add 20 mg of BSA ( $0.2 \%$ BSA in enzyme mix). The dropped BSA powder should dissolve immediately by gently swirling with a hand. Remove the injection needle and the vascular clamp from the heart.

2. Separate the ventricles and atria and transfer each into the enzyme mix supplemented with $0.2 \%$ BSA on the heater mat.
1. Grab the epicardium with two tweezers, and gently tear and pull the ventricles from side to side in the enzyme mix supplemented with $0.2 \%$ BSA into small pieces. Disperse the cells with gentle pipetting (approximately 30 times).

2. Filter the undigested debris through a $100-\mu \mathrm{m}$ mesh cell strainer, and transfer the filtrate to a $15-\mathrm{mL}$ centrifuge tube for centrifugation at $50 \times g$ for 3 min. Resuspend the pelleted cardiomyocytes in prewarmed CIB-Ca ${ }^{2+}-\mathrm{BSA}$ solution, incubate it for 5 $\min$ at $37^{\circ} \mathrm{C}$, and then centrifuge it at $14 \times g$ for 3 $\min$.

3. Resuspend the final precipitated cardiomyocytes in cell resuspension solution (composition is listed in Table 2) and hold it at $37^{\circ} \mathrm{C}$.

3. Isolation of atrial myocytes

1. During the final centrifugation for the ventricular myocyte fraction in step 3.2, start isolating the atrial myocytes. Transfer the atria, stored as in step 3.1, to the prewarmed CIB-Ca ${ }^{2+}-\mathrm{BSA}$ solution, tear it into pieces and dissociate the cells by pipetting with pipette tip at $10 \mu \mathrm{L}$ on the heater mat.

2. Centrifuge the cell mixture at $14 \times g$ for $3 \mathrm{~min}$ and resuspend the pelleted atrial cells with cell resuspension solution.

4. Isolation and culture of cardiac fibroblasts

1. Transfer the supernatant from the first centrifugation in step 3.2 to another $15-\mathrm{mL}$ centrifuge tube, and centrifuge at $190 \times g$ for $5 \mathrm{~min}$. Wash the precipitated cells twice with centrifugation in Dulbecco's Modified Eagle Medium (DMEM), and then suspend the cells

2. Isolation of ventricular myocytes 
with DMEM supplemented with $10 \%$ fetal bovine albumin (FBS) and antibiotics.

2. Plate the final cell fraction in a culture flask (25 $\mathrm{cm}^{2}$ ) and allow the cells to adhere to the bottom of the flask in a humidified atmosphere of $95 \%$ air and $5 \% \mathrm{CO}_{2}$. After 90 min incubation, discard the unattached cells, and add fresh culture medium. Cells should near confluency after approximately 4 days, at which point they should be amplified by trypsinization and seeded into new culture dishes.

\section{Harvesting proteins from atria and ventricles}

1. After perfusion, separate the atria and ventricles, and homogenize them in lysis buffer at a ratio of $10 \mathrm{mg}$ of tissue weight to $100 \mu \mathrm{L}$ of buffer using a small grinder in a 1.5-mL sample tube.

2. Keep the homogenate in ice for 40 min with vortex mixing every $10 \mathrm{~min}$ to extract proteins, and then centrifuge the tube at $15000 \times g$ for $20 \mathrm{~min}$ at $4{ }^{\circ} \mathrm{C}$. Store the supernatant fraction at $-80^{\circ} \mathrm{C}$ as a protein sample.

\section{Immunostaining of isolated heart cells}

NOTE: Immobilization of non-adherent cardiomyocytes to the bottom of the cell imaging dish using biological glue is necessary.

1. Adhesion of isolated cardiomyocytes to a glass-bottom culture dish

1. Before starting cell isolation, coat the glass-bottom culture dish with biological glue (e.g., Cell-Tak) according to the manufacturer's instruction, rinse with DW, and air-dry at room temperature.
2. After resuspension of the isolated cardiomyocytes in $\mathrm{CIB}-\mathrm{Ca}^{2+}-\mathrm{BSA}$ solution, drop the cell suspension on the bottom of the glue-coated dishes, and incubate for $20 \mathrm{~min}$ at room temperature without agitation.

2. Immunostaining

1. Plate the isolated cardiomyocytes on a glass-bottom dish precoated with biological glue and keep it at room temperature for $40 \mathrm{~min}$ to allow the cells to adhere to the dish. Culture cardiac fibroblasts in bottom-glass culture dishes.

2. Rinse cells with phosphate-buffered saline (PBS), and fix them with $4 \%$ paraformaldehyde (PFA) for 5 min with shaking. Wash the fixed cells with PBS for $10 \mathrm{~min}$ three times, and incubate them in blocking-permeabilization solution for $60 \mathrm{~min}$ at room temperature with shaking.

3. Probe cells with primary antibody diluted in blockingpermeabilization solution for $60 \mathrm{~min}$ at room temperature or overnight at $4{ }^{\circ} \mathrm{C}$. Wash the cells with PBS for 10 min three times, and incubate then with fluorescence-labeled secondary antibody for $60 \mathrm{~min}$ at room temperature.

4. After washing them three times with PBS for $10 \mathrm{~min}$, stain the nuclei with DAPI (1:10000 dilution in PBS). Analyze the fluorescent signals using a confocal laser scanning microscope.

\section{Whole-cell patch clamp recordings}

1. Fabricate the patch electrodes from a glass capillaries using a horizontal microelectrode puller. The resistance of the electrode ranged from 2 to $4 \mathrm{M} \Omega$ when filled with a $\mathrm{K}^{+}$-rich pipette solution (Table 2). Transfer an aliquot 
of isolated cardiomyocytes to a recording chamber mounted on the stage of an inverted microscope superfused with Tyrode at a rate of $1 \mathrm{~mL} / \mathrm{min}$ at $36-37^{\circ} \mathrm{C}$.

2. Record action potentials using the perforated patchclamp method with $\mathrm{K}^{+}$-rich pipette solution containing 30 $\mathrm{mg} / \mathrm{mL}$ amphotericin B by applying current pulses of $5-10$ $\mathrm{ms}$ in duration at a rate of $1 \mathrm{~Hz}$ via the patch electrode.

\section{Western blot analyses}

1. In this study, perform a Western blot analysis of smallmolecular-weight proteins, such as atrial marker atrial natriuretic peptide (ANP).

2. Dissolve the protein sample in the final concentration of 1X Sample buffer, 2\% 2' mercaptoethanol, and denature the proteins for $60 \mathrm{~min}$ at $37^{\circ} \mathrm{C}$. Load $20 \mu \mathrm{g}$ of protein into each well, and perform electrophoresis in running buffer with $20 \mathrm{~mA}$ per gel for $120 \mathrm{~min}$.

3. Transfer the protein to a PVDF membrane in transfer buffer at $10 \mathrm{~V}$ for $40 \mathrm{~min}$. Wash the transferred membrane twice with TBST for $5 \mathrm{~min}$, then block with $5 \%$ skim milk in TBST for $60 \mathrm{~min}$ at room temperature, and probe with the primary antibody dissolved in TBST overnight at $4{ }^{\circ} \mathrm{C}$.

4. Wash the membrane 5 times with TBST for $7 \mathrm{~min}$, and incubate it with the secondary antibody diluted in TBST for $120 \mathrm{~min}$ at room temperature.

5. After washing the membrane 5 times with TBST for $7 \mathrm{~min}$, visualize the signals with a chemi-luminescence assay and analyze them with a lumino-image analyzer.

\section{Representative Results}

The principle of this method is simple: the perfusate flows from the left chamber, the aortic valve is opened, and the perfusate runs into the coronary artery in the same direction as the blood run, since the aorta is closed by clamping, which enables the deep perfusion of the myocardium in order to digest the extracellular matrix.

Ventricular myocytes freshly isolated with the present method are shown in Figure 1A. Figure 1B shows enlarged images of the ventricular and atrial myocytes. This isolation procedure resulted in a high yield (70\%-80\%) of rod-shaped quiescent ventricular myocytes from adult mice (8-10 weeks), which were available within roughly $5 \mathrm{~h}$ after isolation (Figure 1C), a similar interval to that when using the traditional Langendorffbased procedure ${ }^{7}$. However, the ratio of freshly isolated viable cells was lower in aged mice of $>2$ years old (Figure 1C). The total number of ventricular myocytes obtained per adult heart using this protocol was approximately $3 \times 10^{6}$ cells, which was similar to the value previously reported ${ }^{7,12}$. The action potentials recorded in the ventricular and atrial myocytes (Figure 1D) were similar to those in cells obtained by the Langendorff-based method ${ }^{10}$. An immunostaining analysis confirmed that the sarcomeric structure of the ventricular myocytes was well-organized with a clearly visible cell membrane (Figure 2A). The individual cardiomyocytes isolated with this method can be directly used in experiments, such as an electrophysiological analysis ${ }^{10}$ or immunostaining experiment. 
Cardiac fibroblasts exist in interstitial spaces. Sufficient digestion of the extracellular matrix results in the isolation of those cells. The isolated cardiac fibroblasts proliferate under culture conditions and can be passaged several times or stored in liquid nitrogen in an appropriate cell reservoir solution. Figure 2B shows that most of the cultured cardiac fibroblasts had transformed into myofibroblasts during subculture, as confirmed by the increased expression of $\alpha$-smooth muscle actin ${ }^{13,14}$. Also, the cardiac progenitors can be isolated with the present

A

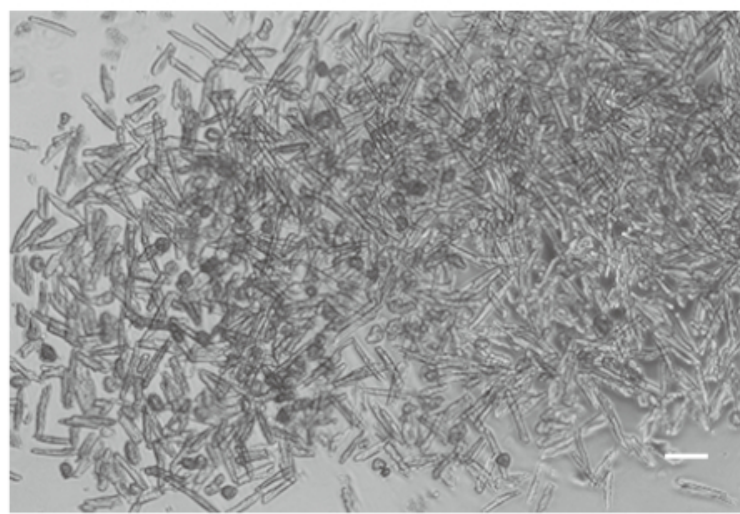

C

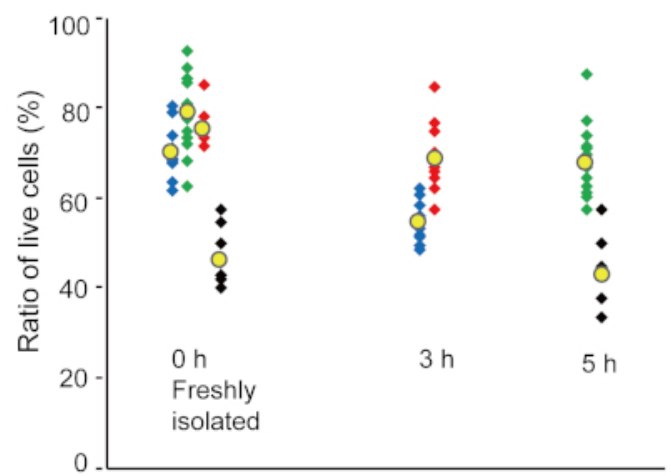

Time after isolation
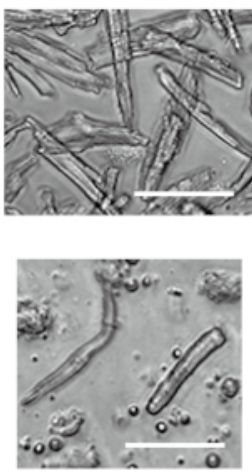

B

method and cultured in appropriate culture medium, which start beating automatically 10,15

Homogenization of the robust myocardium is not easy, especially for cardiac tissue from aged mice, which possesses a large amount of extracellular fibers. After antegrade perfusion, protein from the atria and ventricles can be easily homogenized in the lysis buffer with light force to extract proteins. A Western blot analysis demonstrated the specific expression of ANP in atria but not in ventricles from adult (20 weeks old) and aged (108 weeks old) mice (Figure 3).

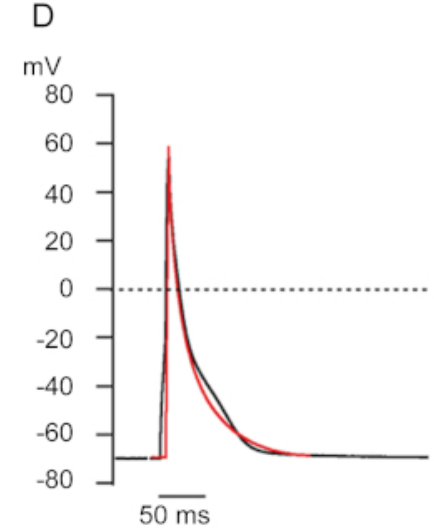

Figure 1. Isolated cardiomyocytes from mice. A. Ventricular myocytes freshly isolated with the antegrade perfusion, with images acquired with low magnification. After the final washing, the cardiomyocytes were resuspended with $2 \mathrm{~mL}$ of cell resuspension solution, $100 \mu \mathrm{L}$ of which was dropped onto the glass-bottom culture dish and cell settlement awaited. 
Bar, $100 \mu \mathrm{m}$. B. Enlarged images of isolated ventricular myocytes (upper) and atrial myocytes (lower). Bar, $100 \mu \mathrm{m} . \mathrm{C}$. Isolated cells were suspended in the cell resuspension solution and stored at $37^{\circ} \mathrm{C}$ for the desired period, and the number of live ventricular myocytes was counted in 10-15 fields under a microscope. Rounded cells were considered to have been irreversibly injured or dead ${ }^{16}$. Green, blue and red symbols were obtained from 3 mice at 8-10 weeks old, and black symbols were from 106 weeks old mouse. Yellow symbol indicates the mean of each group. D. Representative action potentials recorded from ventricular (black) and atrial (red) myocytes of 8-10 mice. The data were obtained from the cells approximately $3 \mathrm{~h}$ after isolation. Please click here to view a larger version of this figure. 


\section{A}
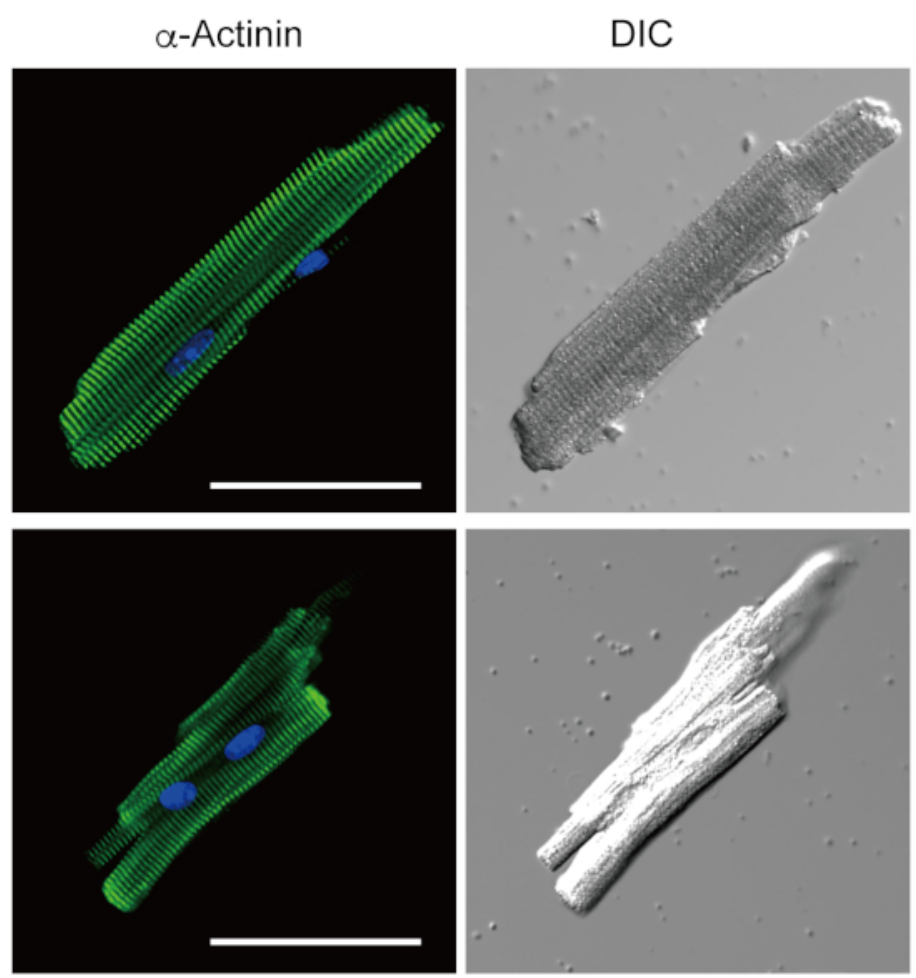

B

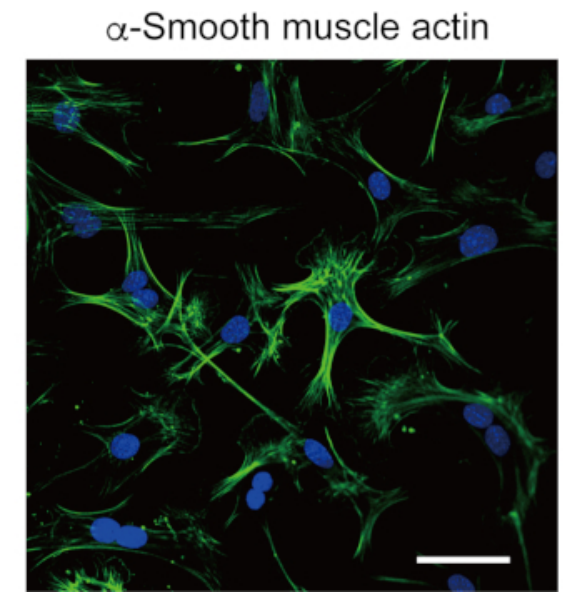

DIC

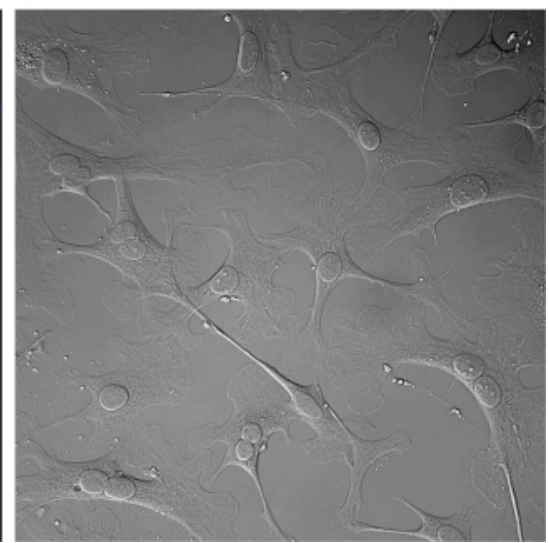

Figure 2. Immunostaining for $\alpha$-actinin in isolated mouse ventricular myocytes and $\alpha$-smooth muscle actin in cultured mouse cardiac fibroblasts. A. Confocal laser scanning microscopy of immunostaining for $\alpha$-actinin (green), DAPI staining for nuclei (blue) and a DIC image of ventricular myocytes isolated from mouse heart with antegrade perfusion. Bar, $50 \mu \mathrm{m}$. B. Immunostaining for $\alpha$-smooth muscle actin (green), DAPI staining for nuclei (blue) and a DIC image of cardiac fibroblasts isolated from mouse heart with antegrade perfusion. Cardiac fibroblasts were cultured for four days. Bar, $100 \mu \mathrm{m}$. Please click here to view a larger version of this figure. 


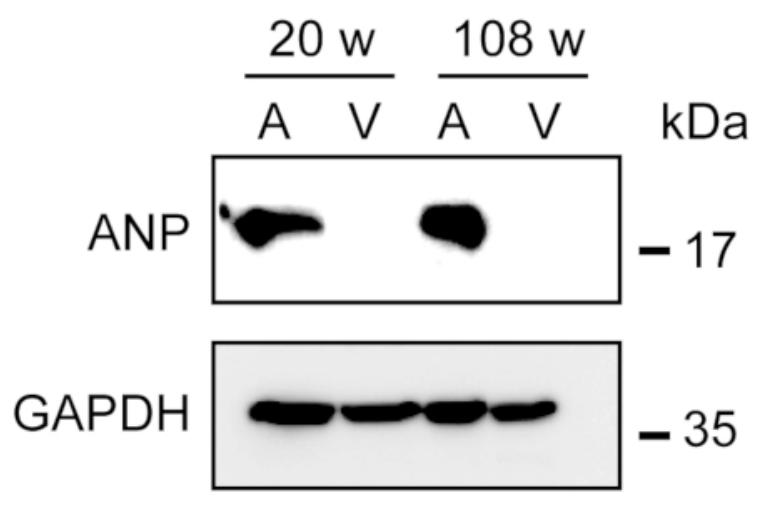

A: Atria

V: Ventricles

Figure 3. Western blot analyses of ANP in atria and ventricles. Western blot analyses for the atrial marker atrial natriuretic peptide (ANP) in atria (A) and ventricles (V) prepared from adult (20 weeks) and aged (108 weeks) hearts. ANP is present in the atria but absent in the ventricles. Use glyceraldehyde 3-phosphate dehydrogenase (GAPDH) as a control house-keeping protein. Please click here to view a larger version of this figure. 


\section{Stock solutions for isolating heart cells}

$10 X \mathrm{CIB}(500 \mathrm{~mL})$

\begin{tabular}{|c|c|}
\hline $\mathrm{NaCl}$ & $37.99 \mathrm{~g}$ \\
\hline $\mathrm{KCl}$ & $2.01 \mathrm{~g}$ \\
\hline $1 \mathrm{M} \mathrm{MgCl}_{2}$ & $2.5 \mathrm{~mL}$ \\
\hline $\mathrm{NaH}_{2} \mathrm{PO}_{4}$ & $0.23 \mathrm{~g}$ \\
\hline HEPES & $29.79 \mathrm{~g}$ \\
\hline DW & Fill up to $500 \mathrm{~mL}$ \\
\hline \multicolumn{2}{|c|}{$100 \mathrm{mM} \mathrm{CaCl} 2$ stock soution } \\
\hline $\mathrm{CaCl}_{2}$ & $100 \mathrm{mM}$ \\
\hline \multicolumn{2}{|c|}{400 mM EGTA stock solution } \\
\hline EGTA & $400 \mathrm{mM}$ \\
\hline \multicolumn{2}{|c|}{ Insulin solution } \\
\hline Insulin & $1 \mathrm{unit} / \mathrm{mL}$ in $0.1 \mathrm{M} \mathrm{HCl}$ \\
\hline \multicolumn{2}{|c|}{ 50X Antibiotics stock solution (20 mL) } \\
\hline Penicillin & $100 \mathrm{mg}$ \\
\hline Streptomycin & $100 \mathrm{mg}$ \\
\hline Phenol red & $1.5 \mathrm{~g}$ \\
\hline DW & $20 \mathrm{~mL}$ and sterilize with filtering \\
\hline \multicolumn{2}{|c|}{ 10X Tyrode solution (1000 mL) } \\
\hline $\mathrm{NaCl}$ & $81.82 \mathrm{~g}$ \\
\hline $\mathrm{KCl}$ & $4.03 \mathrm{~g}$ \\
\hline $1 \mathrm{M} \mathrm{MgCl}_{2}$ & $5 \mathrm{~mL}$ \\
\hline $\mathrm{NaH}_{2} \mathrm{PO}_{4}$ & $0.47 \mathrm{~g}$ \\
\hline HEPES & $11.92 \mathrm{~g}$ \\
\hline $\mathrm{NaOH}$ & $0.8 \mathrm{~g}$ \\
\hline DW & Fill up to $1000 \mathrm{~mL}$ \\
\hline
\end{tabular}




\begin{tabular}{|c|c|}
\hline \multicolumn{2}{|c|}{ Stock solutin for immunostaining } \\
\hline \multicolumn{2}{|c|}{ DAPI stock } \\
\hline DAPI & $2 \mathrm{mg} / \mathrm{mL}$ in methanol \\
\hline \multicolumn{2}{|c|}{ Stock solutions for Western blots } \\
\hline \multicolumn{2}{|c|}{ HEPES buffer (100 mL) } \\
\hline $\mathrm{NaCl}$ & $0.88 \mathrm{~g}$ \\
\hline $400 \mathrm{mM}$ EGTA & $0.25 \mathrm{~mL}$ \\
\hline HEPES & $0.24 \mathrm{~g}$ \\
\hline $1 \mathrm{M} \mathrm{NaOH}$ & adjust $\mathrm{pH}$ to 7.4 \\
\hline DW & Fill up to $500 \mathrm{~mL}$ \\
\hline \multicolumn{2}{|c|}{ Protease inhibitors cocktail } \\
\hline Complete mini & 1 tablet \\
\hline DW & $0.4 \mathrm{~mL}$ \\
\hline
\end{tabular}

Table 1. Description of the stock solutions. Keep stock solutions at $4{ }^{\circ} \mathrm{C}$. Aliquot protease inhibitors cocktail for storage at $-20^{\circ} \mathrm{C}$. 
Solutions for isoltaing heart cells

\begin{tabular}{|c|c|}
\hline \multicolumn{2}{|c|}{ CIB (200 mL) } \\
\hline $10 \times \mathrm{CIB}$ & $20 \mathrm{~mL}$ \\
\hline Insulin solution & $0.01 \mathrm{~mL}$ \\
\hline Glucose & $0.79 \mathrm{~g}$ \\
\hline $1 \mathrm{M} \mathrm{NaOH}$ & $\mathrm{pH}$ adjust to 7.4 \\
\hline DW & Fill up to $200 \mathrm{~mL}$ \\
\hline \multicolumn{2}{|c|}{ Enzyme-mix solution (30 mL) } \\
\hline Collagenase type2 & $30 \mathrm{mg}$ \\
\hline Trypsin & $1.8 \mathrm{mg}$ \\
\hline Protease & $1.8 \mathrm{mg}$ \\
\hline $100 \mathrm{mM} \mathrm{CaCl} 2$ stock solution & $0.09 \mathrm{~mL}$ \\
\hline $\mathrm{CIB}$ & $30 \mathrm{~mL}$ \\
\hline \multicolumn{2}{|c|}{ CIB-Ca ${ }^{2+}-\mathrm{BSA}(15 \mathrm{~mL})$} \\
\hline BSA & $30 \mathrm{mg}$ \\
\hline $100 \mathrm{mM} \mathrm{CaCl} 2$ stock solution & $0.18 \mathrm{~mL}$ \\
\hline CIB & $15 \mathrm{~mL}$ \\
\hline \multicolumn{2}{|c|}{ CIB-EGTA (150 mL) } \\
\hline 400 mM EGTA stock solution & $0.150 \mathrm{~mL}$ \\
\hline $\mathrm{CIB}$ & $150 \mathrm{~mL}$ \\
\hline \multicolumn{2}{|c|}{ Tyrode solution (1000 mL) } \\
\hline 10X Tyrode stock solution & $100 \mathrm{~mL}$ \\
\hline Glucose & $0.99 \mathrm{~g}$ \\
\hline $1 \mathrm{M} \mathrm{CaCl}_{2}$ & $1.8 \mathrm{~mL}$ \\
\hline $1 \mathrm{M} \mathrm{NaOH}$ & $\mathrm{pH}$ adjust to 7.4 \\
\hline DW & Fill up to $1000 \mathrm{~mL}$ \\
\hline \multicolumn{2}{|c|}{ Cell resuspension solution (15 mL) } \\
\hline
\end{tabular}




\begin{tabular}{|c|c|} 
BSA & $30 \mathrm{mg}$ \\
\hline 50X Antibiotics stock solution & $0.3 \mathrm{~mL}$ \\
\hline Tyrode solution & $15 \mathrm{~mL}$ \\
\hline
\end{tabular}

Solutions for immunostaining

Cell adherent solution $(0.3 \mathrm{~mL})$

\begin{tabular}{c|c} 
Cell-Tak & $0.01 \mathrm{~mL}$ \\
$0.1 \mathrm{M} \mathrm{NaHCO}_{3}(\mathrm{pH} 8.0)$ & $0.285 \mathrm{~mL}$ \\
\hline $0.1 \mathrm{M} \mathrm{NaOH}$ & $0.005 \mathrm{~mL}$ \\
\hline
\end{tabular}

Blocking-permeabilizatin solution (10 mL)

\begin{tabular}{c|c} 
Fetal bovine serum & $1 \mathrm{~mL}$ \\
\hline Triton X-100 & $1 \mathrm{~mL}$ \\
\hline 10X PBS & $1 \mathrm{~mL}$ \\
\hline DW & $7 \mathrm{~mL}$ \\
\hline
\end{tabular}

$\mathrm{K}^{+}$rich pipette solution

\begin{tabular}{c|c}
\hline Potassium aspartate & $70 \mathrm{mM}$ \\
\hline $\mathrm{KCl}$ & $50 \mathrm{mM}$ \\
$\mathrm{KH}_{2} \mathrm{PO}_{4}$ & $10 \mathrm{mM}$ \\
\hline $\mathrm{MgSO}_{4}$ & $1 \mathrm{mM}$ \\
\hline ATP disodium salt & $3 \mathrm{mM}$ \\
\hline GTP lithium salt & $0.1 \mathrm{mM}$ \\
\hline EGTA & $5 \mathrm{mM}$ \\
\hline HEPES & $5 \mathrm{mM}$ \\
KOH & pH adjust to 7.2
\end{tabular}

Solutions for Western blots

Lysis buffer (1 mL)

HEPES buffer

Nonidet-P40
$0.86 \mathrm{~mL}$

$0.1 \mathrm{~mL}$ 


\begin{tabular}{|c|c|}
\hline Protease inhibitors cocktail & $0.04 \mathrm{~mL}$ \\
\hline \multicolumn{2}{|c|}{ Runnning buffer (1000 mL) } \\
\hline 10X TG (0.25 M Tris and 1.92 M Glycine) & $100 \mathrm{~mL}$ \\
\hline SDS & $1 \mathrm{~g}$ \\
\hline DW & $900 \mathrm{~mL}$ \\
\hline \multicolumn{2}{|c|}{ Transfer buffer (1000 mL) } \\
\hline $10 \times \mathrm{TG}$ & $100 \mathrm{~mL}$ \\
\hline Methanol & $200 \mathrm{~mL}$ \\
\hline DW & $700 \mathrm{~mL}$ \\
\hline \multicolumn{2}{|c|}{ Blotting buffer (TBST) $(1000 \mathrm{~mL})$} \\
\hline $5 \mathrm{M} \mathrm{NaCl}$ & $20 \mathrm{~mL}$ \\
\hline 2M Tris- $\mathrm{HCl}(\mathrm{pH} 7.5)$ & $5 \mathrm{~mL}$ \\
\hline 10\% Tween 20 & $10 \mathrm{~mL}$ \\
\hline DW & $965 \mathrm{~mL}$ \\
\hline
\end{tabular}

Table 2. Description of the working solutions for isolating heart cells, immunostaining and Western blotting. Prepare all working solutions just before the experiments.

Supplementary Figure 1. Outline of the cell isolation. Flow diagram of the isolation of ventricular and atrial myocytes and cardiac fibroblasts from a single heart. Please click here to download this figure.

\section{Discussion}

Since the heart is highly susceptible to ischemia, the time taken to excise the heart and immerse it in ice-cold CIBEGTA to stop contraction should be kept short as possible $(<1$ $\min )$. This is the first critical step of this method. The second critical step concerns the direction of the heart. The particular orientation of the excised heart in step 2.1.2 makes it easier to see and remove the fat and connective tissues around the aorta. After cleaning around the aorta, place the clamped heart with anterior surface side up on the perfusion plate. The final critical step involves the insertion of the injection needle. When advancing the needle towards the heart, the injection needle should not be detached from the perfusion plate in order to maintain a constant distance from the plate. The position of the insertion is near the apex of the left ventricle. Insert the needle carefully without twisting, since such twisting may enlarge the hole. The depth of the insertion of the needle can be estimated by watching the red mark. If the needle is inserted too deep, the tip may pierce through the ventricular septum and enter the right ventricle or though the mitral valve and enter the left atrium. After confirming the disappearance 
of the blood from the coronary artery, the needle should be fixed with tape to the perfusion plate.

A longer aorta length makes it difficult to clamp the aorta at the right position. If the clamp is too distant from the atria, the heart may rotate after perfusate infusion. To prevent this, cut off the aorta just under the brachiocephalic artery to shorten the aorta before clamping.

If the blood does not begin to discharge after perfusion at an initial speed of $0.5 \mathrm{~mL} / \mathrm{min}$, increase the speed to $1 \mathrm{~mL} / \mathrm{min}$. If that does not help, the injection needle may be positioned incorrectly, such as in the right ventricle, ventricular septum or left myocardial wall. In such a case, remove the needle immediately and try to re-insert it near the apex of the left ventricle. When inserting the needle several times, digested cells may flow out from the opened holes. Note that this does not usually seriously affect the cell isolation.

The operators can monitor the entire process of antegrade perfusion of the heart using a stereoscopic microscope to observe the changes in color and transparency and restarting of the beating of the atria along with the digestion. A total of $10 \mathrm{~mL}$ of enzyme mix should be the maximum required, even for an old heart. In younger hearts (5-7 weeks old), we reduce the volume to $9 \mathrm{~mL}$, which is similar to the approach via retrograde perfusion with the same enzyme mix.

The supernatant at the final centrifugation contains debris, blood cells, and non-myocytes whereas, the pellet contains mainly cardiomyocytes and contaminating non-myocytes, such as fibroblasts and endothelial cells. To purify the cardiomyocytes, more steps are needed. In general, the pellet should be resuspended in the appropriate cell culture medium and preplated for $2 \mathrm{~h}$ at $37^{\circ} \mathrm{C}$ on a tissue cell culture dish, and then gently remove the cardiomyocytes by pipetting and preplating for culture.

The enzyme mix contains a low concentration of $\mathrm{Ca}^{2+}(0.3$ $\mathrm{mM})$. We therefore incubate digested cells in $\mathrm{ClB}^{-\mathrm{Ca}^{2+}}{ }^{2}$ BSA (1.2 $\mathrm{mM} \mathrm{Ca}^{2+}$ ) before the final resuspension with the cell resuspension solution $\left(1.8 \mathrm{mM} \mathrm{Ca}^{2+}\right)$, and the gradual increase in $\mathrm{Ca}^{2+}$ avoids causing cell damage ${ }^{7}$. As long as the isolated cardiomyocytes are intact (quiescent cells with no contraction) this $\mathrm{Ca}^{2+}$-adapting procedure does not affect cell viability in mice. As the damaged cells are dying during this incubation, we consequently obtain a healthy cell group. Similarly, isolated intact atrial myocytes (quiescent cells without irregular contraction) can be stored in the same cell resuspension solution. However, the atrial myocytes tend to be more delicate to be stored compare to the ventricular myocytes.

In the laboratory, this isolation method is almost always successful unless the needle insertion into the left ventricle fails. We have also succeeded in isolating cells from the hypertrophied heart prepared by surgical transverse aortic constriction. However, in aged mice, which often have small myocardial infarctions, perfusion ceases in some places, resulting in incomplete digestion and thus a low yield (Figure 1C), similar to the Langendorff-based retrograde method. In such cases, the distorted shape of the heart can be observed even at the start of perfusion.

This antegrade perfusion method is useful for isolating heart cells from mice of various ages but not larger animals, such as rabbits and guinea pigs. It may be possible to apply this method to neonatal or juvenile rats before weaning.

One of the advantages of this antegrade perfusion method is that it decreases the technical obstacles associated with 
using the Langendorff-based retrograde perfusion method for small mouse hearts. The time required for perfusion is approximately $7 \mathrm{~min}$ with $10 \mathrm{~mL}$ of the enzymes, this short digestion period increases the viability of the cells. In addition, it enables perfusion to be performed through the coronary circulation of the heart, even after the aortic valves have been digested. Isolation of atrial myocytes usually requires Langendorff-based retrograde perfusion and further incubation with enzymes ${ }^{17}$. This antegrade perfusion approach, however, can deeply perfuse the tissue with the enzyme to isolate atrial myocytes.

In experiments using multiple mice, the Langendorff apparatus should be cleaned before perfusing the next heart. However, in the present antegrade method, as long as desired number of instrument sets (e.g., syringes needles and perfusion plates) are prepared in advance, perfusion can be performed continuously.

We herein report the basic methodology of the antegrade perfusion of the mouse heart using the same solutions as the Langendorff-based retrograde perfusion method with no additional chemicals. The composition of the perfusate can be changed to suit the purpose of the experiment, such as using a detergent containing EGTA instead of the enzymes to make a decellularized heart ${ }^{18}$.

\section{Disclosures}

The authors have nothing to disclose.

\section{Acknowledgments}

The authors thank T. Yamamoto and Y. Mori for their assistance in the morphologic experiments. This work was supported by a Grant-in-Aid for Scientific Research (C) from the Japan Society for the Promotion of Science (18K06871 to M.O.K. and 17K08536 to H.M.).

\section{References}

1. Langendorff, $\mathrm{O}$. Untersuchungen am überlebenden Säugethierherzen. Pflügers Archiv: European Journal of Physiology. 61, 291-332 (1898).

2. Berry, M. N., Friend, D. S., Scheuer, J. Morphology and metabolism of intact muscle cells isolated from adult rat heart. Circulation Research. 26 (6), 679-687 (1970).

3. Powell, T., Terrar, D. A., Twist, V. W. Electrical properties of individual cells isolated from adult rat ventricular myocardium. Journal of Physiology. 302, 131-153 (1980).

4. Joshi-Mukherjee, R.et al. Structural and functional plasticity in long-term cultures of adult ventricular myocytes. Journal of Molecular and Cellular Cardiology. 65, 76-87 (2013).

5. Benndorf, K., Boldt, W., Nilius, B. Sodium current in single myocardial mouse cells. Pflügers Archiv: European Journal of Physiology . 404 (2), 190-196 (1985).

6. Zhou, Y. Y.et al. Culture and adenoviral infection of adult mouse cardiac myocytes: methods for cellular genetic physiology. American Journal of Physiology-Heart and Circulatory Physiology. 279 (1), H429-436 (2000).

7. Shioya, T. A simple technique for isolating healthy heart cells from mouse models. Journal of Physiological Sciences. 57 (6), 327-335 (2007).

8. Fiset, C., Clark, R. B., Larsen, T. S., Giles, W. R. A rapidly activating sustained $\mathrm{K}+$ current modulates repolarization and excitation-contraction coupling in adult 
mouse ventricle. Journal of Physiology. 504 (Pt 3) 557-563 (1997).

9. Ackers-Johnson, M.et al. A Simplified, Langendorff-Free Method for Concomitant Isolation of Viable Cardiac Myocytes and Nonmyocytes From the Adult Mouse Heart. Circulation Research. 119 (8), 909-920 (2016).

10. Omatsu-Kanbe, M., Yoshioka, K., Fukunaga, R., Sagawa, H., Matsuura, H. A simple antegrade perfusion method for isolating viable single cardiomyocytes from neonatal to aged mice. Physiological Reports. 6 (9), e13688 (2018).

11. Sambrano, G. R.et al. Navigating the signalling network in mouse cardiac myocytes. Nature. 420 (6916), 712-714 (2002).

12. Limana, F.et al. bcl-2 overexpression promotes myocyte proliferation. Proceedings of the National Academy of Sciences of the United States of America. 99 (9), 6257-6262 (2002).

13. Santiago, J. J.et al. Cardiac fibroblast to myofibroblast differentiation in vivo and in vitro: expression of focal adhesion components in neonatal and adult rat ventricular myofibroblasts. Developmental Dynamics. 239 (6), 1573-1584 (2010).

14. Chistiakov, D. A., Orekhov, A. N., \& Bobryshev, Y. V. The role of cardiac fibroblasts in post-myocardial heart tissue repair. Experimental and Molecular Pathology. 101 (2), 231-240 (2016).

15. Omatsu-Kanbe, M., Matsuura, H. A novel type of self-beating cardiomyocytes in adult mouse ventricles. Biochemical and Biophysical Research Communications. 381 (3), 361-366 (2009).
16. Shan, D., Marchase, R. B., Chatham, J. C. Overexpression of TRPC3 increases apoptosis but not necrosis in response to ischemia-reperfusion in adult mouse cardiomyocytes. American Journal of Physiology. 294 (3), C833-C841 (2008).

17. Nakamura, H.et al. Presence and functional role of the rapidly activating delayed rectifier $K(+)$ current in left and right atria of adult mice. European Journal of Pharmacology. 649 (1-3), 14-22 (2010).

18. Milgroom, A., Ralston, E. Clearing skeletal muscle with CLARITY for light microscopy imaging. Cell Biology International. 40 (4), 478-483 (2016). 